\title{
Brood size and sex ratio in response to host quality and wasp traits in the gregarious parasitoid Oomyzus sokolowskii (Hymenoptera: Eulophidae)
}

\author{
Xianwei Li ${ }^{1}{ }^{\prime}$ Liangting Zhu ${ }^{1}$ ， Ling Meng ${ }^{1}$ ， Baoping Li Corresp. ${ }^{1}$ \\ ${ }^{1}$ School of Plant Protection, Nanjing Agricultural University, No. 1 Weigang Rd, Nanjing, Jiangsu 210095, China \\ Corresponding Author: Baoping Li \\ Email address: Ibp@jnau.edu.cn
}

This laboratory study investigated whether the larval-pupal parasitoid $O$ omyzus sokolowskii females adjust their brood size and sex ratio in response to body size and stage of Plutella xylostella larval hosts, as well as to their own body size and the order of oviposition. These factors were analyzed using multiple regression with simultaneous entry of them and their two-way interactions. Parasioid brood size tended to increase with host body size at parasitism when the $4^{\text {th }}$ instar larval host was attacked, but did not change when the $2^{\text {nd }}$ and $3^{\text {rd }}$ instar larvae were attacked. Parasitoids did not vary in brood size according to their body size, but decreased with their bouts of oviposition on a linear trend from 10 offspring adults emerged per host in the first bout of oviposition down to 8 in the third. Parasitoid offspring sex ratio did not change with host instar, host body weight, wasp body size, and oviposition bout. Proportions of male offspring per brood were from $11 \%$ to $13 \%$ from attacking the $2^{\text {nd }}$ to $4^{\text {th }}$ instar larvae and from $13 \%$ to $16 \%$ across three successive bouts of oviposition, with a large variation for smaller host larvae and wasps. When fewer than 12 offspring were emerged from a host, 1 male was most frequently produced; when more than 12 offspring were emerged, 2 and more males were produced. Our study suggests that $O$. sokolowskii females may optimize their clutch size in response to body size of mature $P$. xylostella larvae, and their sex allocation in response to clutch size. 
1 Brood size and sex ratio in response to host quality and wasp traits in the gregarious

2

3

4

5

6

7

8

9

10

12

13

14

6

11 School of Plant Protection parasitoid Oomyzus sokolowskii (Hymenoptera: Eulophidae)

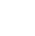

Xianwei Li, Liangting Zhu, Ling Meng, Baoping Li*

(School of Plant Protection, Nanjing Agricultural University, No. 1 Weigang Rd, Nanjing, Jiangsu 210095, P.

R. China)

* Corresponding author: Baoping Li

2 Nanjing Agricultural University

3 Weigang 1\#, Nanjing, Jiangsu Province, Zip code: 210095

4 E-mil: lbp@njau.edu.cn 


\section{ABSTRACT:}

This laboratory study investigated whether the larval-pupal parasitoid Oomyzus sokolowskii females adjust their brood size and sex ratio in response to body size and stage of Plutella xylostella larval hosts, as well as to their own body size and the order of oviposition. These factors were analyzed using multiple regression with simultaneous entry of them and their two-way interactions. Parasioid brood size tended to increase with host body size at parasitism when the $4^{\text {th }}$ instar larval host was attacked, but did not change when the $2^{\text {nd }}$ and $3^{\text {rd }}$ instar larvae were attacked. Parasitoids did not vary in brood size according to their body size, but decreased with their bouts of oviposition on a linear trend from 10 offspring adults emerged per host in the first bout of oviposition down to 8 in the third. Parasitoid offspring sex ratio did not change with host instar, host body weight, wasp body size, and oviposition bout. Proportions of male offspring per brood were from 11

$\%$ to $13 \%$ from attacking the $2^{\text {nd }}$ to $4^{\text {th }}$ instar larvae and from $13 \%$ to $16 \%$ across three successive bouts of oviposition, with a large variation for smaller host larvae and wasps. When fewer than 12 offspring were emerged from a host, 1 male was most frequently produced; when more than 12 offspring were emerged, 2 and more males were produced. Our study suggests that $O$. sokolowskii females may optimize their clutch size in response to body size of mature $P$. xylostella larvae, and their sex allocation in response to clutch size.

\section{INTRODUCTION}

Parasitoids make oviposition decisions depending on a variety of factors, including the quality of hosts and 
characteristics of ovipositing wasps (Charnov et al., 1981; van Alphen \& Visser, 1990; Godfray, 1994; Ellers

\& Jervis, 2003). Host quality for parasitoid development is often assumed to scale with host size and this

pattern is true for idiobiont parasitoids, which arrest host growth at the time of oviposition (Askew \& Shaw,

1986; King, 1990; Otto \& Mackauer, 1998). This pattern, however, may not be universally applicable to

koinobiont parasitoids, which allow the host to continue to develop after it has been parasitized (Werren, 1984;

Waage, 1986; Mackauer, Sequeira \& Otto, 1997; Harvey, Sano \& Tanaka, 2010), and thus the future resources

for developing koinobiont larvae can vary depending on the host age or development stage at the time of

oviposition (Harvey \& Strand, 2002; Harvey, 2005), though there are some koinobiont parasitoids still

preferring larger body hosts (King, 1989; Elzinga, Harvey \& Biere, 2003; Kant, Minor \& Trewick, 2012). In

addition to host quality, parasitoid oviposition decisions may also depend on characteristics of ovipositing

wasps, including their body size and states, such as egg load, age, and nutrition states. The wasp size is

frequently considered to be the main target for selection (Godfray, 1994; Ode \& Strand, 1995; Bezemer,

Harvey \& Mills, 2005). It can affect fitness by influencing searching efficiency, longevity, or egg supplies

(Mayhew \& Heitmans, 2000; Milonas, 2005; Jervis, Ellers \& Harvey, 2008; Kasamatsu \& Abe, 2015). In

addition, it may also influence the quality of host attacked, in that a small female wasp may not be able to use a

large, good quality host that is more effective in defense against attacks (Godfray, 1994; Henry, Ma \&

Roitberg, 2009). Parasitoid state can affect many parasitoid behaviors (van Alphen \& Visser, 1990; Roitberg \&

Bernard, 2008; Harvey, Poelman \& Tanaka, 2013). For example, oviposition experience and physiological

constraints, such as egg load, can influence parasitoid oviposition decisions (Cloutier et al., 1991; Henneman

et al., 1995; Sirot, Ploye \& Bernstein, 1997; Ueno, 1999; Rosenheim et al., 2008; Dieckhoff et al., 2014).

Therefore, parasitoids may integrate the information provided by a variety of cues about hosts and themselves 
to make oviposition decisions.

Oomyzus sokolowskii (Kurdjumov) is a gregarious larval-pupal koinobiont endoparasitoid of the diamondback moth, Plutella xylostella (L.) (Talekar \& Shelton, 1993; Talekar \& Hu, 1996; Silva-Torres et al., 2009), which is one of major herbivorous pests on cruciferous crops (Furlong \& Zalucki, 2007; Zalucki et al., 2012; Li et al., 2016). Because P. xylostella populations have developed resistance to numerous pesticides (Liu, Tzeng \& Sun, 1981; Ferré et al., 1991; Li et al., 2006), biological control with natural enemies offers greater potential (Talekar \& Shelton, 1993; Delvare, 2004; Sarfraz, Keddie \& Dosdall, 2005). The parasitoid $O$. sokolowskii has been found parasitizing P. xylostella worldwide (Wang et al., 1999; Nakamura \& Noda, 2001; Silva-Torres et al., 2009; Li, Niu \& Liu, 2014), showing the potential for biological control of P. xylostella (Talekar \& Hu, 1996; Furlong, Wright \& Dosdall, 2013). For O. sokolowskii developmental performances in attacking $P$. xylostella larvae of different instars, two non-choice studies are not consistent in their conclusions, though the female wasp prefers mature larvae under choice circumstances (Talekar \& $\mathrm{Hu}, 1996)$. While Wang et al. (1999) showed similar performances in the development time, number, and sex ratio of offspring in attacking host larvae of different instars, Nakamura \& Noda (2002) showed that $O$. sokolowskii brood size increased with host body size when hosts for parasitism were confined to the prepupal stage. It would be interesting to examine whether or not parasitoid brood size varies as a function of host body size depending on host larval stage at parasitism. In addition, states of ovipositing wasps may influence oviposition decisions. It has been shown that older $O$. sokolowskii females declined in the progeny produced per female and the number of parasitoids emerged per host (Silva-Torres, Barros \& Torres, 2009; Sow et al., 2013). However, scant attention has been paid to the effect of $O$. sokolowskii female body size on its oviposition behavior. Therefore, to fully understand $O$. sokolowskii oviposition strategy, we need studies involving both host quality and wasp 
traits.

This laboratory study aimed to answer the question: How do O. sokolowskii females make oviposition decisions on brood size and sex ratio in response to both host quality and their own traits? We examined combined effects of body size and age of $P$. xylostella larvae as well as body size and ovipositing order of the female wasp, by using mutiple regression models with simultaneous entry of these factors and their two-way interactions. Our study provides new data to the understanding of oviposition behavior in gregarious parasitoids.

\section{MATERIALS \& METHODS}

\section{Insects}

Plutella xylostella was collected in the early spring 2014 from a pakchoi (Brassica chinensis L.) field on eastern suburb of Nanjing, Jiangsu, and thereafter maintained on potted pakchoi seedlings in insectary at $25 \pm$ $1{ }^{\circ} \mathrm{C}, 60 \pm 5 \% \mathrm{RH}$, and a photoperiod of $16: 8 \mathrm{~h}(\mathrm{~L}: \mathrm{D})$.

Oomyzus sokolowskii was obtained from the Key Laboratory of Northwest Loess Plateau Crop Pest Management of Ministry of Agriculture of China, Northwest A\&F University, Yangling, Shaanxi. It was maintained with P. xylostella $4^{\text {th }}$ instar larvae as hosts in the insectary. A group of 4 host larvae was introduced into a $4 \mathrm{ml}$ centrifuge tube, which was covered by 100 mesh plastic screen for ventilation and supplied with a piece of fresh pakchoi leaf as food. Then a female $O$. sokolowskii was released into the tube. After $24 \mathrm{~h}$ the larvae were removed from the tube and transferred individually to 10 -cm-diameter Petri dishes containing excised fresh pakchoi leaves, which were replaced daily. The host pupae parasitized (different from normal ones by dark body color) were collected in groups in vials, where emerged parasitoid adults were maintained 
100

101

102

103

104

105

106

107

108

109

110

111

112

113

114

115

116

117

118

119

120

for one day to ensure fully mating. Naive females emerged within one day were used in the experiments.

\section{Oviposition behavior}

Plutella xylostella $2^{\text {nd }}, 3^{\text {rd }}$ and $4^{\text {th }}$ instar larvae were used as hosts. Each larva was individually exposed to parasitism after weighed (Mettler Toledo, AL204-IC, with the measurement accuracy of $0.01 \mathrm{mg}$ ). After introduced into a $4 \mathrm{ml}$ centrifuge tube containing a host larva, a female wasp was continuously observed until a bout of oviposition was completed. The wasp then was removed and immediately introduced into another tube containing a same-aged host larva for the second bout of oviposition; then for the third. Three successive bouts of oviposition took ca. 5-6 h to be accomplished by a wasp, which was considered as a replicate. The number of replicates for the $2^{\text {nd }}, 3^{\text {rd }}$, and $4^{\text {th }}$ instar host larvae was 32,43 , and 34 , respectively. After the three bouts of oviposition, the wasp was collected and measured in the right hind tibia length (HTL) under the microscope as a measure of body size. The parasitized host larvae were individually reared on excised pakchoi leaves in tubes until parasitoid offspring adults emerged. Emerged wasps from each host were counted as a measure of brood size, and their sexes determined by their antennae with long hairs on each segments in males and without the hairs in females. When the parasitized hosts were dead before wasps emerged, the hosts were dissected to count immature parasitoids as a measure of brood size, but their sexes were not identifiable.

\section{Data Analyses}

General linear mixed-effects models (LMMs) were used to analyze brood size (number of wasps emerged), which was transformed by logarithm before the analysis to satisfy the underlying assumptions. Generalized linear mixed-effects models (GLMMs) were used to analyze sex ratio (binary variable) with a binomial error.

The subject wasp was included in the model as a random effects variable to control for the correlation between three oviposition bouts of each wasp. Host body weight, host instar (nominal), wasp size, the temporal order of 
121

122

123

124

125

126

127

128

129

130

131

132

133

134

135

136

137

138

139

140

141

oviposition (ordinal), and their second-way interactions were firstly included as fixed effects variables in the full model, then excluded from it when they did not have significant effects, using Type III Wald Chi-Square test to evaluate the significance of the terms by comparing the fit of full model to the fit of the reduced model without each of them. Orthogonal polynomial contrasts were used to detect trends (either linear or quadratic) in parasitoid performance with increasing bouts of oviposition. When there was a significant interaction between host instar and body weight, general linear models were separately used to detect the relationship between brood size and host body weight for each of host instars examined. To analyze the relationship between the number of males in a brood and brood size, the tree model was used to determine the threshold for splitting the brood size, of which the number of males in a brood changed as a step function. The mixed effects models were fitted by the laplace approximation using 'Ime4' version 1.1-10 (Bates et al, 2015). Data analyses were performed with R (R Development Core Team, 2014).

\section{RESULTS}

Parasitoid brood size was affected by host body weight and instar interaction (Wald Chi-Square test, $\chi^{2}=$ $6.30, P=0.04)$ and the order of oviposition $\left(\chi^{2}=18.01, P<0.001\right)$, but not by wasp HTL $\left(\chi^{2}=0.01, P=0.94\right)$.

The regression analysis of brood size in relation to host body weight for different host instars showed no significant relations for the $2^{\text {nd }}\left(\chi^{2}=2.09, P=0.14\right)$ and $3^{\text {rd }}\left(\chi^{2}=0.90, P=0.34\right)$ instars. Brood size ranged from 4 to 21 wasps with an average of $9.0 \pm 0.3( \pm \mathrm{SE})$ in the $2^{\text {nd }}$ instar hosts that varied in body weight from 0.01 to $0.03 \mathrm{mg}$, and 2 to 19 with an average of $9.1 \pm 0.2( \pm \mathrm{SE})$ in the $3^{\text {rd }}$ instar hosts that varied in body weight from 0.03 to $0.14 \mathrm{mg}$ (Fig. 1A, B). But the analysis showed a marginally significant relation between brood size and body weight of the $4^{\text {th }}$ instar hosts $\left(\chi^{2}=3.65, P=0.048\right)$, with a gradual increase by ca $20 \%$ in 
142

143

144

145

146

147

148

149

150

151

152

153

154

155

156

157

158

159

160

161

162

brood size with each increase of $0.1 \mathrm{mg}$ in host body weight; brood size ranged from 4 to 14 wasps with an average of $9.3 \pm 0.3$ ( \pm SE) across host body weight from 0.18 to $0.69 \mathrm{mg}$ (Fig. 1C). Brood size did not change with ovipositing wasp HTL (Fig 1D), but varied with the temporal sequence of oviposition, decreasing on a linear trend over increasing bouts of oviposition (slope $=-0.11, \mathrm{SE}=0.03, t=4.24$ ) from 10 offspring adults emerged per host in the first oviposition bout down to 8 in the third (Fig. 1E).

Offspring sex ratio was not affected by host instar (Wald Chi-Square test, $\chi^{2}=0.89, P=0.64$ ), host body weight $\left(\chi^{2}=0.16, P=0.69\right)$, wasp HTL $\left(\chi^{2}=0.01, P=0.93\right)$ and the temporal sequence of oviposition $\left(\chi^{2}=\right.$ $3.69, P=0.16)$. Average proportions of male offspring from attacking host larvae of different instars were 0.14 $(\mathrm{SD}=0.10)$ for the $2^{\text {nd }}$ and $0.14(\mathrm{SD}=0.11)$ the $3^{\text {rd }}$ instar larvae, with two extremely high sex ratios (male proportion $>0.5)$ for each of the two instars; the mean proportion of males was $0.13(\mathrm{SD}=0.05)$ for the $4^{\text {th }}$ instar hosts (Fig. 2A). Male proportion of offspring did not change with host body weight (Fig. 2B) and ovipositing wasp HTL (Fig. 2C), with a few extremely high sex ratios produced from very small hosts (body weight $<0.1 \mathrm{mg}$ ) or wasps (body length $<0.45 \mathrm{~mm}$ ). Proportions of males for successive bouts of oviposition were $0.13(\mathrm{SD}=0.09)$ for the $1^{\text {st }}, 0.13(\mathrm{SD}=0.06)$ the $2^{\text {nd }}$, and $0.16(\mathrm{SD}=0.11)$ the $3^{\text {rd }}$, with two much higher sex ratios produced from the $1^{\text {st }}$ and $3^{\text {rd }}$ bouts of oviposition, respectively (Fig. 2D). The number of males per brood changed as a step function of brood size, which split at 12 with a significant difference between the two split groups $\left(F_{1,232}=68.17, P<0.001\right)$. A brood fewer than 12 contained 1 male (mean $\left.=1.2, \mathrm{SD}=0.49\right)$, while brood more than 12 had 2 males (mean $=1.68, \mathrm{SD}=2.24)$ with a few broods containing extremely numerous males (Fig. 2E).

\section{DISCUSSION}

PeerJ reviewing PDF | (2016:07:12380:2:0:NEW 15 Dec 2016) 
In this study, we showed that $O$. sokolowskii offspring brood size tended to increase with body size of $P$.

xylostella $4^{\text {th }}$ instar larvae, but did not change with that of the $2^{\text {nd }}$ and $3^{\text {rd }}$ instar larvae. The pattern exhibited in the $4^{\text {th }}$ instar larval hosts is similar to that shown in prepupal hosts documented by Nakamura $\&$ Noda (2002).

We therefore assume that $O$. sokolowskii females may take the cues associated with body size of only older

larval hosts when evaluating host quality to make the oviposition decision on clutch size. Host larvae close to

pupation can provide more accurate information about host quality in terms of body size than younger ones do

because body size changes much less with growth in mature than younger larvae. Such evaluation of host quality can be advantageous for koinobiont parasitoids to attack older larval hosts, such as larval-pupal

parasitoids. Female $O$. sokolowskii prefers to parasitize older than younger $P$. xylostella larvae (including

prepupae) (Talekar \& Hu, 1996). Though differential mortality rates during offspring development among

different host instars may somehow potentially contribute to the pattern we observed in $O$. sokolowskii, such

effect might be negligible because brood sizes were quite close to each other between host instars observed in

our study, while the number of eggs (primary clutch size) are not different among these instars (Nakamura \&

Noda, 2002).

Body size is one of important attributes for female wasps because it is correlated with several components of the fitness (King, 1987; Blackburn, 1991; King, 1993; Ellers \& Jervis, 2003; Henry, Ma \& Roitberg, 2009). In the case of gregarious parasitoids, the fitness of a female parasitoid can be strongly correlated with not only the number of eggs laid per host but also the number of hosts attacked. Our study showed that $O$. sokolowskii brood size did not change with body size of ovipositing wasps. We therefore assume that larger O. sokolowskii 
184

186

the only host of $O$. sokolowskii, $P$. xylostella larvae tend to clump together in the early stage, disperse locally as they grow, and then aggregate again during pupation (Chua \& Lim, 1979; Furlong, Wright \& Dosdall, 2013).

For the performance of a slight, linear decrease in brood size across successive bouts of oviposition shown in our study, the most likely explanation is that egg expenditure on successive bouts of oviposition leads to a steady decline in number of eggs available to oviposit when a group of hosts are encountered in quick succession. Daily decrease in offspring production occurs in O. sokolowskii (Wang et al., 1999; Li, Niu \& Liu, 2014), as well as in other gregarious parasitoids, such as in Cotesia glomeratus L. attacking the white butterfly

Pieris rapae (L.) (Ikawa \& Suzuki, 1982).

Our study did not show the influence of host size, host life stage, wasp body size and oviposition sequence on parasitoid offspring sex ratio. Invariable sex ratios in response to host age and size were previously observed in O. sokolowskii (Wang et al., 1999; Nakamura \& Noda, 2002; Silva-Torres et al., 2009). The lack of sex allocation response to changes in host size in $O$. sokolowskii may exclude widely held Charnov's host quality hypothesis as an explanation. The Charnov's hypothesis (Charnov et al., 1981) was developed specifically for solitary parasitoids, in which offspring body size is strongly correlated with host body size. Host size for many idiobiontic solitary parasitoids is thought to more strongly influence female than male fitness (Werren, 1984; Charnov \& Skinner, 1985; King, 1993). In the case of gregarious parasitoids, however, the fitness of the adult wasp is determined primarily by the clutch size and possibly the sex composition (Griffiths \& Godfray, 1988; Hardy, Griffiths \& Godfray, 1992; Godfray, 1994; Ode \& Heinz, 2002). Maintaining constant, female-biased sex ratios in response to variation in host quality and wasp traits in $O$. sokolowskii suggests that this parasitoid may be able to adjust offspring sex ratios. Female-biased sex ratios are 
205

206

207

208

209

210

211

212

213

214

215

216

217

218

219

220

221

222

223

224

225

most frequently exhibited in gregarious parasitoids, where there is a high probability the mating occurs between siblings and that brothers compete together for mates (Godfray, 1994; Ode and Hunter, 2002; Ode and Hardy, 2008). Such observations can be explained by Hamilton's (1967) theory of local mate competition (LMC), which predicts that a single female should lay only enough males to fertilize all her daughters. In the case of $O$. sokolowskii where sib-mating is common among offspring from a host, foundresses are expected under LMC to adjust the number of males in response to brood size. Our study showed that $O$. sokolowskii produced 1 male in most of broods under 12 wasps, and 2 males in broods over 12, except a few largest broods with extremely numerous males from attacking very small host larvae. We suspect that these few broods were consequences of constraints under non-choice circumstances in the experiments. When these extreme data points are excluded, our study is the same as Nakamura \& Noda (2002) in finding that only 1 male was produced when the brood contained fewer than 9 offspring and 2 to 4 males when it contained more than 9 offspring.

\section{ACKNOWLEDGEMENTS}

We thank Yuanxing Sun for providing O. sokoloskii and Lintao Li for the help in the experiments, and the two reviewers for providing helpful comments on improving the manuscript.

\section{REFERENCES}

Askew RR, Shaw MR. 1986. Parasitoid communities: Their size, structure and development. In: Waage JK, Greathead D, ed. Insect parasitoids. London: Academic Press, 225-264.

Bates D, Mächler M, Bolker BM, Walker SC. 2015. Fitting linear mixed-effects models using lme4. Journal of 
Statistical Software 67:1-48. DOI: 10.18637/jss.v067.i01.

Bezemer TM, Harvey JA, Mills NJ. 2005. Influence of adult nutrition on the relationship between body size and reproductive parameters in a parasitoid wasp. Ecological Entomology 30:571-580. DOI: 10.1111/j.0307-6946.2005.00726.x.

Blackburn TM. 1991. Evidence for a fast slow continuum of life history traits among parasitoid hymenoptera. Functional Ecology 5:65-74. DOI: 10.2307/2389556.

Charnov EL, Losden Hartogh RL, Jones WT, Assem JVD.1981. Sex ratio evolution in a variable environment. Nature 289:27-33. DOI: 10.1038/289027a0.

Charnov EL, Skinner SW. 1985. Complementary approaches to the understanding of parasitoid oviposition decisions. Environmental Entomology 14:383-391. DOI: 10.1093/ee/14.4.383.

Chua TH, Lim BH. 1979. Distribution pattern of diamondback moth, Plutella xylostella (L.) (Lepidoptera: Plutellidae) on choy-sum plants. Zeitschrift Für Angewandte Entomologie 88:170-175. DOI: 10.1111/j.1439-0418.1979.tb02492.x.

Cloutier C, Lévesque CA, Eaves DM, Mackauer M. 1991. Maternal adjustment of sex ratio in response to host size in the aphid parasitoid Ephedrus californicus. Canadian Journal of Zoology 69:1489-1495. DOI: 10.1139/z91-208.

Delvare G. 2004. The taxonomic status and role of hymenoptera in biological control of DBM, Plutella xylostella (L.) (Lepidoptera: Plutellidae). In: Kirk AA, Bordat D, ed. Improving biocontrol of Plutella xylostella. Proceedings of the international symposium. France: Montpellier, 17-49.

Dieckhoff D, Theobald JC, Wäckers FL, Heimpel GE. 2014. Egg load dynamics and the risk of egg and time limitation experienced by an aphid parasitoid in the field. Ecology and Evolution 4:1739-1750. DOI: 
10.1002/ece3.1023.

248 Ellers J, Jervis M. 2003. Body size and the timing of egg production in parasitoid wasps. Oikos 102:164-172.

249 DOI: $10.1034 / \mathrm{j} .1600-0706.2003 .12285 . \mathrm{x}$.

250 Elzinga JA, Harvey JA, Biere A. 2003. The effects of host weight at parasitism on fitness correlates of the

251 gregarious koinobiont parasitoid Microplitis tristis and consequences for food consumption by its host,

Hadena bicruris. Entomologia Experimentalis et Applicata 108:95-106. DOI: 10.1046/j.1570-

7458.2003.00072.x.

Ferré J, Real MD, Van Rie J, Jansens S, Peferoen M. 1991. Resistance to the Bacillus thuringiensis 
268 Harvey JA. 2005. Factors affecting the evolution of development strategies in parasitoid wasps: the importance

269 of functional constraints and incorporating complexity. Entomologia Experimentalis et Applicata 117:1-13.

$270 \quad$ DOI: $10.1111 / \mathrm{j} .1570-7458.2005 .00348 . x$.

271 Harvey JA, Poelman EH, Tanaka T. 2013. Intrinsic inter- and intraspecific competition in parasitoid wasps.

272 Annual Review of Entomology 58:333-351. DOI: 10.1146/annurev-ento-120811-153622.

273 Harvey JA, Sano T, Tanaka T. 2010. Differential host growth regulation by the solitary endoparasitoid,

274 Meteorus pulchriconis in two hosts of greatly differing mass. Journal of Insect Physiology 56:1178-1183.

275 DOI: 10.1016/j.jinsphys.2010.03.018.

276

277

278

279

280

281

282

283

284

285

286

287

288

Harvey JA, Strand MR. 2002. The developmental strategies of endoparasitoid wasps vary with host feeding

ecology. Ecology 83:2439-2451. DOI: 10.1890/0012-9658(2002)083[2439:TDSOEW]2.0.CO;2.

Henneman ML, Papaj DR, Figueredo AJ, Vet LEM. 1995. Egg-laying experience and acceptance of parasitized hosts by the parasitoid, Leptopilina heterotoma (Hymenoptera: Eucoilidae). Journal of Insect Behavior 8:331-342. DOI: 10.1007/BF01989362.

Henry LM, Ma BO, Roitberg BD. 2009. Size-mediated adaptive foraging: a host-selection strategy for insect parasitoids. Oecologia 161:433-445. DOI: 10.1007/s00442-009-138-2.

Ikawa T, Suzuki Y. 1982. Ovipositional experience of the gregarious parasitoid, Apanteles glomeratus (Hymenoptera: Braconidae), influencing her discrimination of the host larvae, Pieris rapae crucivora. Applied Entomology and Zoology 17:119-126.

Jervis MA, Ellers J, Harvey JA. 2008. Resource acquisition, allocation, and utilization in parasitoid reproductive strategies. Annual Review of Entomology 53:361-385. DOI: 10.1146/annurev.ento.53.103106.093433. 
289 Kant R, Minor MA, Trewick SA. 2012. Fitness gain in a koinobiont parasitoid Diaeretiella rapae 290 (Hymenoptera: Aphidiidae) by parasitising hosts of different ages. Journal of Asia-Pacific Entomology 15:83-87. DOI: 10.1016/j.aspen.2011.08.011.

Kasamatsu E, Abe J. 2015. Influence of body size on fecundity and sperm management in the parasitoid wasp Anisopteromalus calandrae. Physiological Entomology 40:223-231. DOI: 10.1111/phen.12106.

King BH. 1987. Offspring sex ratios in parasitoid wasps. Quarterly Review of Biology 62:367-396. DOI: $10.1086 / 415618$

King BH. 1989. Host-size-dependent sex ratios among parasitoid wasps: does host growth matter? Oecologia 78:420-426. DOI: 10.1007/BF00379119.

King BH. 1990. Sex ratio manipulation by the parasitoid wasp Spalangia cameroni in response to host age: a test of the host-size model. Evolutionary Ecology 4:149-156. DOI: 10.1007/BF02270912.

King BH. 1993. Sex ratio manipulation by parasitoid wasps. In: Wrensch DL, Ebert MA, ed. Evolution and diversity of sex ratio in insect and mites. New York: Chapman \& Hall, 418-441.

Li A, Yang Y, Wu S, Li C, Wu Y. 2006. Investigation of resistance mechanisms to fipronil in diamondback 99.3.914. Zoology 49:67-75. DOI: 10.1007/s13355-013-0225-z. 
310 Li Z, Zalucki MP, Yonow T, Kriticos DJ, Bao H, Chen H, Hu Z, Feng X, Furlong MJ. 2016. Population

311 dynamics and management of diamondback moth (Plutella xylostella) in China: the relative contributions

312 of climate, natural enemies and cropping patterns. Bulletin of Entomological Research 106:197-214. DOI: 10.1017/S0007485315001017.

Mackauer M, Sequeira R, Otto M. 1997. Growth and development in parasitoid wasps: adaptation to variable 191-203.

Ode PJ, Strand MR. 1995. Progeny and sex allocation decisions of the polyembryonic wasp Copidosoma 
floridanum. Journal of Animal Ecology 64:213-224. DOI: 10.2307/5756.

332 Ode PJ, Hardy ICW. 2008. Parasitoid sex ratios and biological control. In: Wajnberg E, Bernstein C, van

333 Alphen J, ed. Behavioral ecology of insect parasitoids: from theoretical approaches to field applications.

UK: Blackwell Publishing, 253-291.

Ode PJ, Hunter MS. 2002. Sex ratios of parasitic Hymenoptera with unusual life-histories. In: Hardy ICW, ed.

Sex ratios: concepts and research methods. UK: Cambridge University Press, 218-234.

Otto M, Mackauer M. 1998. The development strategy of an idiobiont ectoparasitoid, Dendrocerus carpenteri: 
352

353

354

355

356

357

358

359

360

361

362

363

364

365

366

367

368

369

370

371

372

Entomology 38:512-519. DOI: 10.1590/S1519-566X2009000400013.

Silva-Torres CSA, Ramos Filho IT, Torres JB, Barros R. 2009. Superparasitism and host size effects in Oomyzus sokolowskii, a parasitoid of diamondback moth. Entomologia Experimentalis et Applicata 133:65-

73. DOI: 10.1111/j.1570-7458.2009.00903.x.

Sirot E, Ploye H, Bernstein C. 1997. State dependent superparasitism in a solitary parasitoid: egg load and survival. Behavioral Ecology 8:226-232. DOI: 10.1093/beheco/8.2.226.

Sow G, Arvanitakis L, Niassy S, Diarra K, Bordat D. 2013. Life history traits of Oomyzus sokolowskii Kurdjumov (Hymenoptera: Eulophidae), a parasitoid of the diamondback moth. African Entomology 21:231-238. DOI: 10.4001/003.021.0202.

Talekar NS, Hu WJ. 1996. Characteristics of parasitism of Plutella xylostella (Lep., Plutellidae) by Oomyzus sokolowskii (Hym., Eulophidae). BioControl 41:45-52. DOI: 10.1007/BF02893291.

Talekar NS, Shelton AM. 1993. Biology, ecology and management of the diamondback moth. Annual Review of Entomology 38:275-301. DOI: 10.1146/annurev.en.38.010193.001423.

Ueno T. 1999. Host size dependent sex ratio in a parasitoid wasp. Researches on Population Ecology 41:47-57.

DOI: $10.1007 /$ PL00011982.

van Alphen JJM, Visser ME. 1990. Superparasitism as an adaptive strategy for insect parasitoids. Annual Review of Entomology 35:57-79. DOI: 10.1146/annurev.en.35.010190.000423.

Waage JK. 1986. Family planning in parasitoids: adaptive patterns of progeny and sex allocation. In: Waage JK, Greathead D, ed. Insect parasitoids, London: Academic Press, 63-95.

Wang XG, Liu SS, Guo SJ, Liu WC. 1999. Effects of host stages and temperature on population parameters of Oomyzus sokolowskii, a larval-pupal parasitoid of Plutella xylostella. BioControl 44:391-402. DOI: 
374 Werren JH. 1984. A model for sex ratio selection in parasitic wasps: local mate competition and host quality 375 effects. Netherlands Journal of Zoology 34:123-143. DOI: 10.1163/002829684X00056. of the world's major insect pests, Plutella xylostella (Lepidoptera: Plutellidae): just how long is a piece of string? Journal of Economic Entomology 105:1115-1129. DOI: 10.1603/EC121107. 


\section{Figure 1}

Number of wasps emerged per host (brood size) in relation to host quality and wasp traits.

Fig. 1 Numbers of offspring parasitoids per host (brood size) in relation to host body weight of the $2^{\text {nd }}(A), 3^{\text {rd }}(B)$ and $4^{\text {th }}(C)$ instar larvae at oviposition, wasp body length $(D)$, and the order of oviposition (E). The solid line in panel $\mathrm{C}$ represents a linear relationship between brood size and host body weight with intercept 8.09 and slope 3.33, with a 95\% confidence region (grey shade). The line in panel E represents a linear trend. 

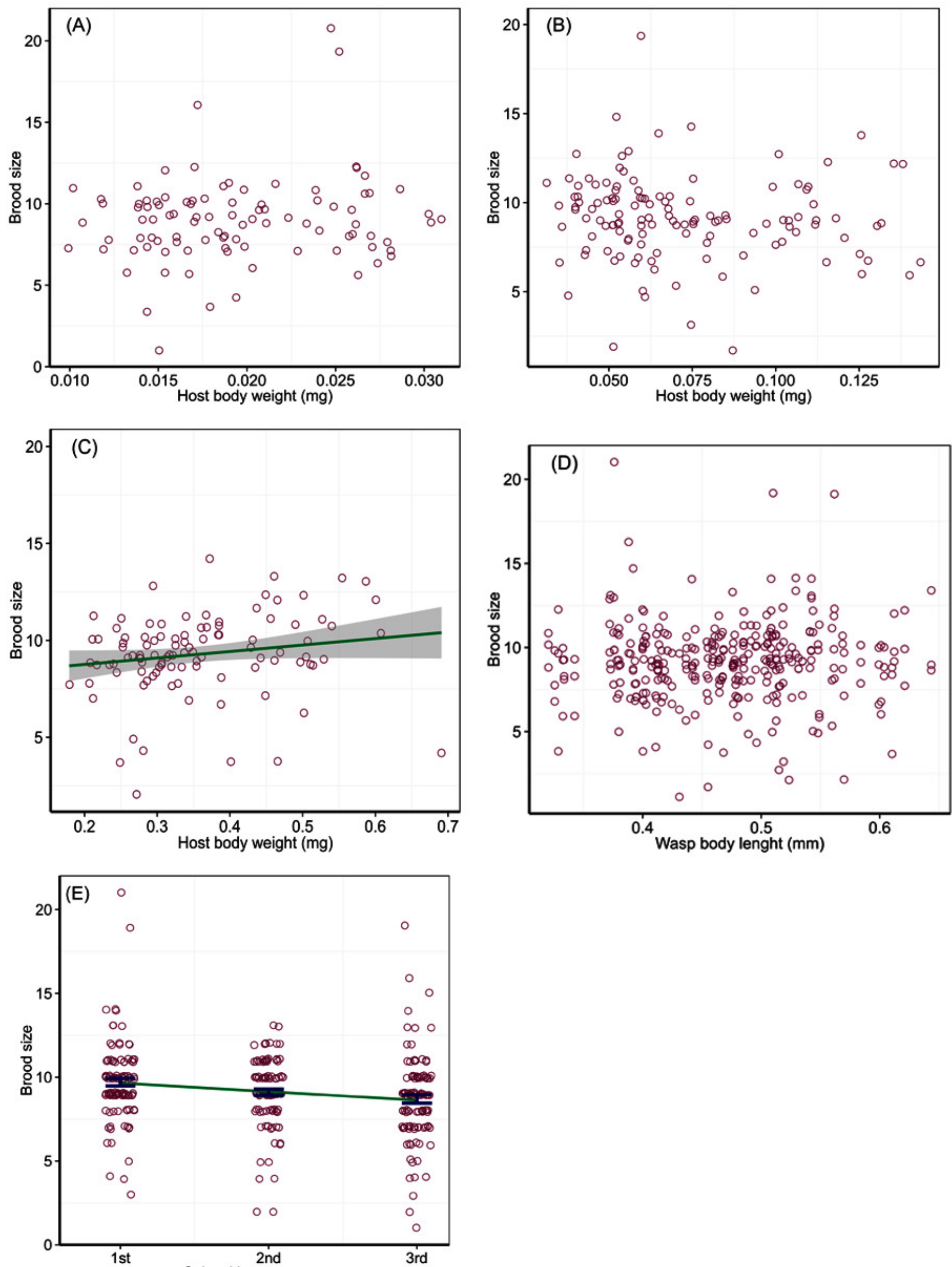


\section{Figure 2}

Brood sex ratio in response to host quality and wasp traits.

Fig. 2 Sex ratios in relation to host instar (A), host body weight (B), wasp body length (C) and bout of oviposition (D), and the relationship (E) between the number of males and offspring emerged (brood size) per host with a curve fitted by locally weighted polynomial method with a $95 \%$ confidence region (grey shade). Bars in panels $A$ and $D$ are mean $\pm \mathrm{SE}$. 

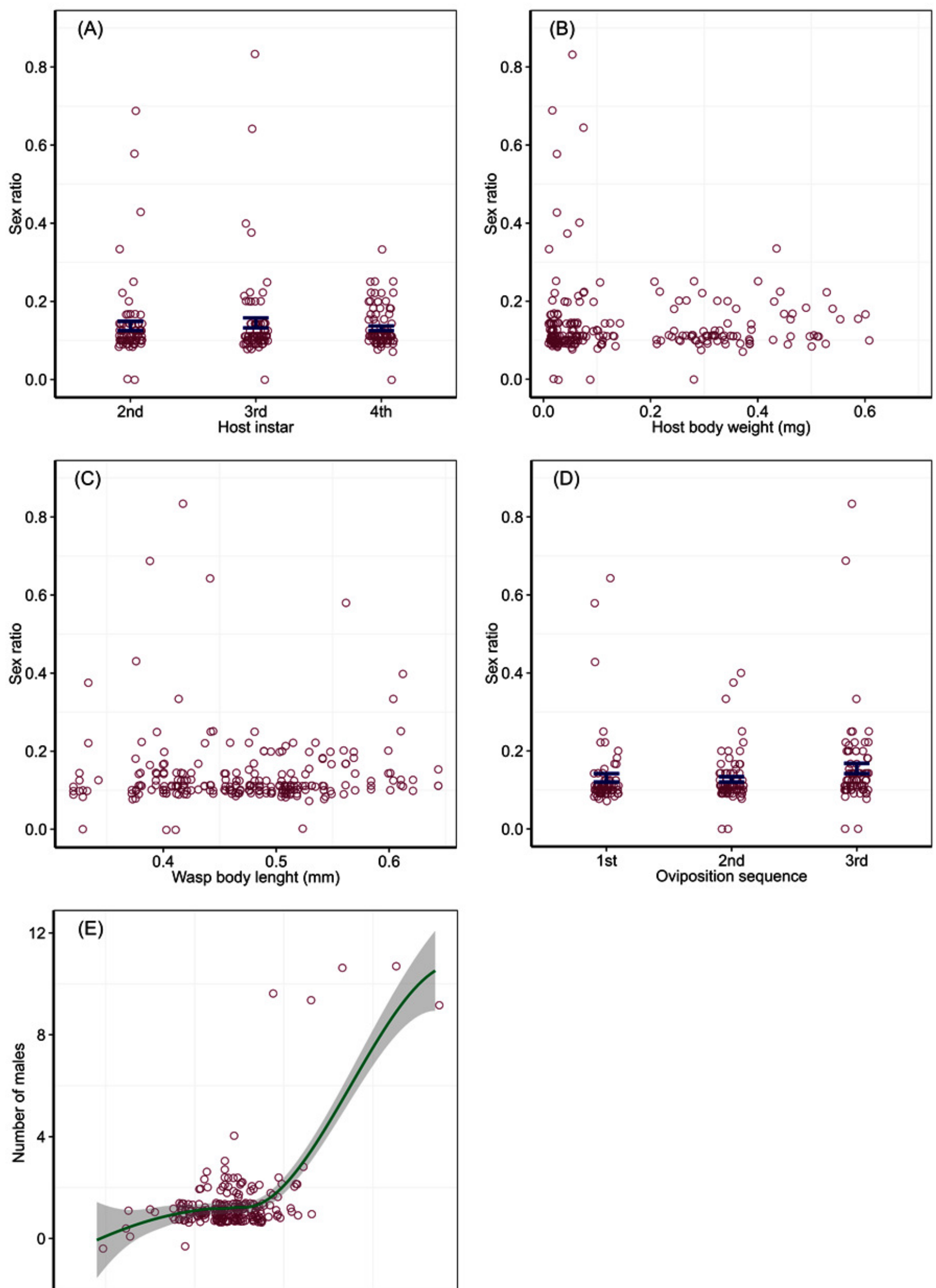